\title{
Attitudes, Instructional Practices and Difficulties Faced by English Teachers While Teaching Through 'Quality Drive'
}

\author{
Muhammad Arfan Lodhi ${ }^{1}$, Rabia Jabeen ${ }^{2}$, Sadaf Mustafa ${ }^{2}$, Naheed Siddique ${ }^{2}$, Aqsa Liaqat ${ }^{2} \&$ Irum Robab $^{3}$ \\ ${ }^{1}$ Higher Education Department Collegiate Wing, Punjab \\ ${ }^{2}$ M.Phil Scholar, NCBA\&E University, Lahore \\ ${ }^{3}$ Government College Women University, Sialkot \\ Correspondence: Muhammad Arfan Lodhi, Higher Education Department Collegiate Wing, Punjab Pakistan.
}

Received: March 3, 2018 Accepted: April 9, 2019 Online Published: April 11, 2019

doi: 10.5539/elt.v12n5p URL: https://doi.org/10.5539/elt.v12n5p79

\begin{abstract}
Quality Education is the bedrock foundation of primary level of educational pyramid. It helps not only in the development of individuals but also improve their living standard at academic and professional domains. Government of Punjab has initiated a literacy and numeracy drive movement to enhance the literacy rate. English is the major focus of concern in Literacy and Numeracy drive (LND). Present study has been conducted to study the attitudes, instructional practices and difficulties faced by the English primary teachers while teaching English through quality drive. The study was descriptive in nature based on the mixed method i.e. quantitative and qualitative approach. It was conducted in the rural and urban schools of the elementary wing of tehsil Khanpur district Rahimyar Khan. The results reflected that teachers showed positive behavior towards teaching English through LND. But they faced many problems like unhealthy environment, lack of facilities, influence of mother tongue, non cooperative behavior of parents and lack of interest in learning English. The weak base of grammar, vocabulary, pronunciation, spellings and comprehension are also the basic problems. It showed that traditional method is in common practice for teaching English language. The study recommends improvement in the mechanism of literacy and numeracy drive to produce better outcomes of English teaching.
\end{abstract}

Keywords: QD (Quality Drive), LND (Literacy and Numeracy drive), capacity building trainings, ESL teaching, government schools

\section{Introduction}

As a multilingual country, Pakistan represents a complex linguistic society. It is included in the list of those countries where English is considered as a key to modernization and development. For this purpose, it is taught at all academic level. Primary English teacher considers it a herculean task to teach English to a student at primary level in rural and urban areas. But English is the need of time and the focus of all the education policy developer is to produce efficiency and skill in this target language. Primary sector is considered as the base of all the educational hierarchy. So, in every country all the educational thinkers try to develop strategies to improve the condition of primary level to strengthen the foundation of education. In Punjab, different initiatives have been taken in the previous years to improve the quality of education which has brought remarkable changes in education system. "Barho Punjab, Parho Punjab" is the logo that is carried out in whole Punjab. Different strategies and different projects' have been initiated to create awareness among the people about the importance of primary education. To improve the quality of education, a movement named "Quality Drive" is also initiated in recent years. Then this quality drive is further narrowed down as "Literacy and Numeracy Drive" i.e. called LND. In Which basics of English, Urdu and Math has been taught specially to class three. Students learning outcomes are designed to make this literacy and numeracy drive successful. Computer mediated technology is used to motivate the students. Tablets are introduced at ground level to remove the hesitation of students. MCQs type test is designed on the proposed SLOs. This is an effective step to measure the progress of students and to evaluate the standards of education in Pakistan. Different researches have been conducted on the difficulties and problems faced by the English teacher at primary level. D. W. Johnson and R. T. Johnson (2009) described that language is the biggest policy of development in education and English language is at the top. In Pakistan English has been taught as the compulsory subject at primary level without taking into consideration that who will teach it. $\mathrm{Hu},(2005)$ and Nunan, (2003) reported about the unavailability of trained primary school teacher of 
English. Teachers find problems and difficulties in teaching English at primary level. The motivation of the learner is also difficult, as in rural areas children find it difficult to percept the things in English because they have little contact with speakers of the language (Ho, 2003).

\subsection{Statement of the Problem}

Since English is not the native language of Pakistan. In Pakistan ESL teachers face many challenges while teaching English at primary level because at primary level, students are aware of their mother tongue only. They feel difficulty in understanding English as a second language. The government of Punjab took an initiative to improve the quality of Education at Primary level. As it is the base of educational hierarchy. A movement of quality drive was introduced in the mid of 2015. According to that every educational or administrational manager had to adopt two schools and they had to teach there two days in a week. But the system flopped due to the busy schedule of the educational administration and the poor attention on the adopted schools. With the passage of time, teachers faced many problems regarding instructional techniques used in the procedure and interaction with the students. After that Literacy and numeracy drive was introduced to teach the basics of English, Math and Urdu. The purpose of the study was to observe the attitude of the teachers to improve quality education, the instructional techniques used by the teachers, difficulties faced by the teachers and suggestions to improve the mechanism.

\subsection{Research Objectives}

1) To explore the behavior and attitudes of primary school teachers towards teaching English through quality drive at primary level.

2) To identify the difficulties and problems faced by the primary school teachers towards teaching English through quality drive at Primary level.

3) To find the teaching strategies used by primary school teachers while teaching English through quality drive at primary level.

4) To determine the effect of capacity building trainings of the primary school teachers on the teaching performance.

5) To discuss the suggestions to improve the effect of literacy and numeracy drive on the learning of English at Primary level.

\subsection{Research Questions}

1) What is the behavior and attitude of primary school teachers towards teaching English through quality drive at primary level?

2) What are the difficulties and problems faced by the primary school teachers towards teaching English through quality drive at Primary level?

3) What are the teaching strategies used by primary school teachers while teaching English through quality drive at primary level?

4) What is the effect of capacity building trainings of the primary school teachers on the teaching performance while teaching English at primary level?

5) What suggestions can be given to improve the effect of literacy and numeracy drive on the learning of English at Primary level?

\subsection{Significance of the Study}

The present study is significant for the understanding of the problems faced by the primary teachers, while practicing English at primary level in the section of LND i.e., teaching of vocabulary, sentence completion, picture identification, and comprehension to class three. It is also helpful to measure the attitudes and behavior of the teachers towards LND, and it also assessed the effectiveness of the mechanism of literacy and numeracy drive. Many studies have been carried out to explore the attitudes, difficulties and strategies used by English teachers while teaching English, but a little have been conducted in the field of literacy and numeracy drive. So, this study is helpful in paving the way for further researches and in providing suggestions for the improvement of mechanism of Literacy and Numeracy drive especially regarding English. 


\section{Literature Review}

\subsection{Education System in Pakistan}

The history of education system in Pakistan goes back to the independence of Pakistan when British left subcontinent leaving behind the state in a miserable condition. According to a research study of Qayyum et al (2015), Our educational system is still under the influence of colonialism, we cannot get rid of this colonial system, because the developed countries never let us alone to implement the system according to our needs, Moreover, the elite class in our country never let us to escape from the chains of slavery. As a result after the independence, the general perception prevailed that, Pakistan is still under the influence of British system. As this education system is producing only the followers, who try to enslave their own countryman, who teach to hate their own people.

The education system in Pakistan comprises six levels:

1). Pre-School (For the age group of 3 to 5 Years)

2). Primary (For grade one to five)

3). Middle (For grade six to eight)

4). Secondary school certificate or SSC, (for grade ninth and tenth)

5). Intermediate or Higher Secondary School Certificate or HSSC, (for grade eleven and twelve)

6). University Programs for under graduate and graduate degrees.

\subsection{Medium of Instructions in Pakistani Classrooms}

Since the time of its creation in 1947, Pakistan has been facing a wide scaled linguistic variation and language conflict. Like other post-colonial countries, Pakistan is also confronting with the issues of language policies and educational policies (Mansoor, 2004; Mustafa, 2011; Rahman, 1996; Rassool \& Mansoor, 2007). The unpredictable attitude of the government is obvious with the fact that since the creation of Pakistan, It had issued 22 policy credentials on language in education policies (Rahman, 2004). In her dissertation on the language policy of Pakistan, Amir (2008) discussed the medium of instruction in educational policies of Pakistan. She mentioned that English is not used as a foreign language but it is mainly used as a medium of upward mobility, it creates class differences. She investigated chronicles of English as a medium of instruction in Pakistan through three phases, i.e. the mid eighteenth century, the 1970, and the present decade. She analyzed that colonial system divided this country in the upper and lower class and medium of instruction remained English for the people who can afford it and the masses used vernacular or Urdu language. In another research article, the position and Status of English in Pakistan, Haque (1983) wrote that, in Pakistan linguistic picture is complex. It is a country of diverse languages. Bacherman (2007); Tong et al. (2008), reflected in their studies that the acquisition of second language is not affected by the use of mother tongue as a medium of instruction. But Hong (2008) concluded that the constant use of translation in the mother tongue hinder the developmental process of the second language. It is very important to have clear idea about medium of instruction as language plays a vital role in communication, in exchanging of ideas and concepts with each other (Aziz, 2003). English was the medium of communication with Englishmen in all the table talks of Quaid e Azam, Allama Iqbal, Liaqat Ali Khan and Sir Sayed Ahmad Khan etc. In this regard, Shamim (2011) stated, "English is the passport to success and upwards social mobility" in many societies where English is either a second or a foreign language. Different countries such as India, Malaysia, Pakistan, and Saudi Arabia have been taking steps to provide quality of education in the medium of English (Nunan, 2003). So, in this age of globalization, the importance of English cannot be denied.

\subsection{Attitudes and Behavior of English Teachers}

According to Oxford dictionary, attitude is a settled way of thinking or feeling about something. The attitude and behavior of parents and teacher towards the learner produce a deep effect on the learning capability of the student. Attitude is defined by Anastasi (1957), as an internal motivation to react against a pre set stimuli. It is a response of the individual towards the situation and objects based on his personal experience and mental set up. Similarly, the performance of the individual in his profession is affected by the attitude. The same is the case with the teaching. According to Phan, Kho, and Chung, (2013), In order to struggle in the globalised world, teachers play a vital role to encourage the students to be adept in English. Shammen (2004), observed that attitude of the teacher like culture effect the learning of the students. Generally, it is observed that the rate of success of the student is directly proportional to the attitude of the teacher. According to McLeod (1992), in the 
development of quality education not only the pedagogical knowledge of the teacher is important but the attitudes and behavior of the teacher are also the prime factors.

\subsubsection{Instructional Practices of English Teachers}

Instructional practices are the teaching techniques that teachers adopt for the better interaction in the classroom. These teaching methods are like vehicles which help the teacher to enhance the outcome of the learning of the students. Effective teaching methods play a key role to achieve the desired learning experience of the students. Different researchers have identified different primary sources for the instructional practices. Some of the strategies are given below that teachers use as a primary source. According to Brooks and Thurston (2010); Kanevsky (2011); Reis, McCoach, Little, Muller, and Kaniskan (2011), the use of Differentiate Instruction i.e. DI in the instructional practices can enhance the learning ability of the students, similarly the researchers like (Kanevsky, 2011; Lantolf \& Poehner, 2010) argue that use of Vigotsky's zone of proximal development (ZPD) in the instructional practice can also produce the same effect. The findings of the above studies show that differentiation is effective in instructional practices.

\subsubsection{Difficulties Faced by ESL Teachers}

According to Mundy (2008), Teacher is the main and essential character in an educational reform, specially, in the whole process that goes on in the classrooms. However, the training of the teachers effect a lot on their innovative skill, but still there are lots of challenges that impede the learning process. In the study, Mekhlafi and Nagarathnam (2011) investigated the problems faced by the EFL teachers in teaching grammar. The study pointed out that in the process of language learning, grammar is the basic entity. Generally, it is considered that it is difficult to teach grammar but in language learning classroom it is unavoidable. In his study Wiriyachitra (2001), focused on the situation of English language teaching and learning in Thailand. He investigated the problems faced by the English language teachers and the suggestion for the improvement in the process of teaching language.

\subsection{Quality Drive}

Quality education has been taken as a priority area in a sub regional meeting of South Asian ministers in Kathmandu in April 2001.It was discussed in the meeting that in spite of all the efforts the results are not satisfactory .An urgent need of remedy was felt to meet the goals of EFA 2015. In a Dakar framework of Action mentioned in UNESCO (2000), it was targeted to ensure improvement in all areas of quality education with excellence, and to ensure all the learning outcomes especially in literacy and numeracy life skills.

\subsubsection{Literacy and Numeracy Drive}

Literacy and numeracy drive has been started by the government of Punjab in collaboration with the Punjab information technology Board along with the assistance of monitoring and evaluation assistants. The purpose was to evaluate the performance of schools and to check the proficiency of the students of grade three in English, Urdu and Math. Monitoring and evaluation assistants (MEAs) have been provided with Tab devices. On monthly basis, an average of 4,900 public schools is visited with 2,400 visits daily. It means that test of almost 14,000 students have been taken daily.

\section{Research Methodology}

\subsection{Research Design}

The present study is descriptive in its nature. It is mixed method research. The population of this research has been taken from the elementary and primary government schools of district Rahimyar Khan. The sample used in this study comprises 100 male and 100 female teachers from rural and urban areas, and five primary classes from rural area and five primary classes from urban area. The sample of schools was determined through convenient sampling technique. On the other hand, teachers were selected with equal gender proportion by using systematic sampling technique. Prior consent was obtained from the selected respondents of the study. The anonymity and confidentiality of the respondents was ensured during the whole process.

Table 1. Sample statistics

\begin{tabular}{llll}
\hline Participants & Teachers & Urban Schools & Rural Schools \\
\hline Male & 100 & 5 & 5 \\
Female & 100 & 5 & 5 \\
Total & 200 & 10 & 10 \\
\hline
\end{tabular}




\subsection{Data Collection Tools}

The observation tools used in this study are questionnaire and observation. Data was collected from teachers by using self developed questionnaire. The questionnaire was piloted and validated before its administration. Similarly, observation checklist was used to gather data during classroom observations.

\subsection{Data Analysis}

The collected data was analyzed by using software of the statistic packages for social sciences (SPSS) version 20.0. The simple parameter of measurements like frequency, mean and standard deviation (SD) were used to analyze the collected data. For every item the responses were analyzed on five point scale and the open ended questions were analyzed qualitatively. The findings were drawn on the basis of the analysis of the collected data.

\section{Findings and Discussions}

The analysis of the data indicates that during the teaching of LND English class, some of the teachers checked the previous knowledge of the students while others didn't take interest in knowing about the previous knowledge of the students. Some of the teachers used ice breakers before started teaching the lesson. Teachers mostly used activities for picture identification and sentence completion but the frequency of using activities for sentence completion is found greater than the frequency of using activities for comprehension practice. Though, the frequency of communicating the students in target language is low than the frequency of using mother tongue, but it is observed that students feel more ease in mother tongue and teaching become more effective while using mother tongue than the use of target language. So, the frequency of responding in the mother tongue is greater than the frequency of responding in target language. The behavior of a teacher as a facilitator goes parallel with the authoritative behavior in the classroom. But the learning environment is found better in the classroom where teacher's behavior was as a facilitator. Teacher talk time is greater than students talk time in most of the classes. Data shows that although the percentage of taking interest in using tab for LND practice is high but the frequency rate shows that teachers feels more ease in working on whiteboard. Similarly, Most of the teachers think that the continuous practice of the test of literacy and numeracy drive is a burden, they think that there is just the repetition of the same questions and there is nothing new in the test, on the other hand, they are strongly agreed that it is a good initiative in increasing the literacy rate. Teaching of English at primary level is a very tough task but the learning behavior of the students of rural areas is almost same as of the urban areas. When we discuss about the difficulties faced by the teachers then data shows that the lack of interest on the part of the students as well as of the parents is a great hindrance in learning English. Some teachers think that jumble questions in LND English practice test confuse the students and they just do memorization and can't focus on concept formation. But some teachers are in the favor that LND is helpful in concept making of the students about the given students learning outcomes. It is indicated by the data that the frequency of concept development is slightly greater than the memorization of habitual questions. The percentage of the need of teacher's training regarding English LND is comparatively high. It means that for the practice of the test of literacy and numeracy drive and for the effectiveness of its outcome on learning, a skilled, trained and qualified teacher is needed. The analysis shows that use of mother tongue is also a hindrance in teaching English. But mother tongue can't be avoided in any case. But the ratio of using mother tongue in rural areas is greater than in the urban areas. However, the frequency of behavior about LND English test is almost same for the students of rural and urban areas. As far as instructional practice is concerned, teachers use different methods to teach English at primary level and to ensure the effectiveness of LND, but the frequency of using traditional method is greater than the frequency of using direct method. In some places audio lingual method is also in practice and some new educators also teach through communicative language teaching approach. For setting the goals and targets, students learning outcomes are already designed for the teachers and students, as the questions in the monthly practice test and the test taken on tab by MEA, are used to be selected in the criteria of these SLOs. So, teachers follow the lessons according to the students learning outcomes. Moreover, teacher uses tab for teaching, in fact, the frequency of responses is greater for the benefits of using tab for the picture identification, sentence completion, and retention of students. Teachers are of the view that tab is helpful in developing the interest of the students in learning English and it is also helpful in providing positive feedback in determining the learning capability of the students. The fear of conduction of test by the monitoring evaluation officer is also dominant and it is a great factor in the negative respond of students on tab during test. So, there is need to remove the fear of monitoring and evaluation assistants for better results of LND English practice tests. Besides these the difficulties faced by the teachers include lack of co operation of parents, poverty, over-crowded classrooms, lack of interest due to absence of students, difficulty in understanding comprehension on Tab, weak base of students, horrible pressure of MEA, illiteracy of parents, hesitation of learning English and effect of mother tongue on the learning of the students. Data indicates that English teaching and learning is a very tough task for the 
multilingual students. However the statistics showed that students feel pleasure and interest in using tab for learning the basic concepts of English. The identification of objects and sentence completion can easily be understood by using tab. While responding in open ended questions, teachers suggested that well qualified teachers should be recruited for primary classes who must be well aware of the new technology. The better results can be obtained if the new package of LND material is introduced with new skills. Moreover, the analysis of data showed that all the four skills are not equally proportionate in the literacy and numeracy drive.

\subsection{Interpretation of Research Questions}

4.1.1 What Is the Behavior and Attitude of Primary School Teachers Towards Teaching English Through Quality Drive at Primary Level?

English is the international language; it's not the native language of Pakistan. Literacy and numeracy drive has been initiated to improve the quality education. The findings of data reflect that teachers' behavior and attitude towards teaching English through LND is positive. They think that it is a good initiative in improving the quality education but some teachers are of the view that it is no more than a burden or nightmare. Though the responses of the teachers shows that they consider it helpful in developing the basic concepts of English regarding helping verbs, pronouns, completion of the sentences, spellings and comprehension but the dominance of memorization can't be denied due to the repetition of same habitual questions in the practice test of LND. Data also reflect that teaching the basic concepts of English through LND and by practicing on Tab is slightly a time consuming work.

4.1.2 What Are the Difficulties and Problems Faced by the Primary School Teachers Towards Teaching English Through Quality Drive at Primary Level?

The data reflected that teachers have been facing certain difficulties in teaching the basic concepts of English related to helping verbs, pronouns, grammar, and completion of sentences, spellings and comprehension. The basic difficulty is that English is the non native language and it creates difficulty in perception. Furthermore, the lacks of parents and teachers interest are also responsible for the poor outcomes. The analysis of data reflected that lack of qualified English teachers at primary level also cause difficulty. The observation of findings showed that other factors causing difficulty are lack of facilities, overcrowded class rooms, absence of the students and fear of monitoring and evaluation assistant. The base of the students mostly in rural areas is weak and they are unaware of the basic rules of grammar. Mostly the attention is not paid on teaching the basic concepts. The unawareness of practice on Tab on the part of teachers in mostly schools also causes difficulty. Students also feel hesitation on practicing on Tab. The lack of training of English LND for teachers is also a factor of hindrance in progress.

4.1.3 What Are the Teaching Strategies Used by Primary School Teachers While Teaching English Through Quality Drive at Primary Level?

The analysis of data reflected that mostly teachers use traditional method for teaching LND English. Data also reflected that though at primary level use of direct method is difficult but in some areas it is in practice. Mostly teachers use mother tongue to clear the basic concepts of English LND. The findings show that most of the teachers take interest in teaching through tab and in practicing through it. Most of the teachers teach on the basis of students learning outcomes. Some teachers design activities to clear the concepts and some of them use audio visual aids to enhance the learning of basic concepts. While drilling method is also in practice in some areas.

4.1.4 What Is the Effect of Capacity Building Trainings of the Primary School Teachers on the Teaching Performance While Teaching English at Primary Level?

The analysis of data indicates that capacity building trainings of primary teachers are so much important. There should be English language trainings of teachers for improvement in the English component of literacy and numeracy drive. Data reflected that with continuous trainings of teachers the impact of literacy and numeracy drive can be improved. It also denotes that teaching performance is directly proportional to the maximum and purposeful trainings of the teachers.

4.1.5 What Suggestions Can Be Given to Improve the Effect of Literacy and Numeracy Drive on the Learning of English at Primary Level?

The findings of data shows that different strategies can be adopted to improve the effect of literacy and numeracy drive on the learning of English at primary level. Keeping in view that English is not the native language of the country; the focus should be on the understanding of the basic concepts for better perception. There should not be the word to word translation rather the whole meaning should be intelligible. The stress should not be on the completion of syllabus only rather the basic students learning outcomes should be in focus. The students learning outcomes of literacy and numeracy drive of English should match the syllabus of the text 
books of English. Well-qualified and properly trained teachers are needed. Teaching strategies should be adopted according to the environment of the classrooms and caliber of the students. Data also reflected that the effect of literacy and numeracy drive can be improved by designing different interesting activities and by developing worksheets for students. The hesitation of the students to use tab can be removed through frequent practice. Lit-num new package material is needed to be introduced with new activities. Findings also shows that besides improving reading skills the activities to improve listening skills should also are in practice for better understanding of English. The findings reflected that the focus should also be on the enhancement of confidence level of students. Teachers should provide positive feedback to the students. Overall, teacher should be equipped with the latest techniques and knowledge.

\subsection{Implications of the Study}

1) The prime focus of the Punjab government is in improving the literacy rate and literacy and numeracy drive is seriously focused by the authorities. So this study is helpful in detecting the attitude and behavior of primary English teachers towards LND.

2) The current study highlights the difficulties faced by the primary English teachers in the field regarding LND.

3) The study is helpful in devising different strategies to overcome the problems faced by the English primary teacher while teaching English through literacy and numeracy drive.

4) The study is also helpful in finding the instructional practices used in the field by English primary teachers for teaching through LND.

5) The study also focuses on the importance of literacy and numeracy drive regarding English at primary level.

\section{Conclusion}

The current study evaluated and discussed the behavior of English primary teachers towards English while teaching through literacy and numeracy drive. They consider that English LND practice through tab is a good initiative but in some aspects it is a time consuming and boring task due to repetition of same practice questions. Primary English teacher faces many difficulties in teaching the basic concepts like the use of helping verb, pronoun, completion of sentences and comprehension. The accent of the teachers also causes problem as the students can't pronounce well with the poor listening and it creates difficulty in perception. The level of difficulty varies from male to female as well as from the teachers and students of rural areas to urban areas. The basic difficulties that teachers feel are the lack of parents' cooperation, trained teachers and lack of facilities in the schools. Poverty, pressure of MEA and illiteracy of parents are also the greatest hindrance in the process of effective teaching. The findings also reflected some strategies to overcome the difficulties faced by the English primary teachers regarding LND. These strategies include the development of work sheet for LND class, focus on the improvement of reading skills, and introduction of listening skills' activities in the students learning outcomes of literacy and numeracy drive. As far as the instructional practices are concerned the findings reflect that the frequency of using traditional method is greater than the use of direct method. Use of mother tongue is also found dominant during teaching practices.

\subsection{Recommendations}

1) The study recommended that new strategies should be devised to overcome the difficulties faced by the English teachers at primary level.

2) It is also recommended to improve the mechanism of literacy and numeracy drive to achieve the objectives.

3) It is recommended to introduce some activities in literacy and numeracy drive to improve listening skills of the students.

4) Finally, it is suggested for the researchers to undertake similar kind of research to introduce new techniques of teaching English through literacy and numeracy drive.

\section{References}

Amir, A. (2008). Chronicles of English language in Pakistan, A discourse analysis of milestones in the language policy of Pakistan. An Unpublished thesis: Stockholm University.

Anastasi, C. (1957) Attitude of in-service and pre-service primary school teachers. Journal of Education Psychology, 36(3), 1-5. 
Aspin, D. N., \& Chapman, J. D. (1994). Quality Schooling: A Pragmatic Approach to Some Current Problems and Issues. London: Cassell.

Aziz, B. N. (2003). Peranan bahasa dalam pembelajaran kimia. Buletin Persatuan Pendidikan Sains dan Matematik Johor. Jil. 12, Bil., 1, 59 -64.

Bacherman, D. M. (2007). The Use of Students' First Language in Second-language Learning in a Computer based Environment. (Ph.D. dissertation, Walden University, United States -- Minnesota. Retrieved April 13, 2018, from Dissertations \& Theses: Full Text database).

Brooks, K., \& Thurston, L. P. (2010). English language learner academic engagement and instructional grouping configurations. American Secondary Education, 39(1), 45-60.

Haque. (1983). The position and status of English in Pakistan. World Lansu.se En\&h, 2(I), 6-9.

Ho, W. K. (2003). English language teaching in Asia today: An overview. In W. K. Ho, \& R. Y. L. Wong (Eds.), English language teaching in East Asia today: Changing policies and practices (pp. 1-32). Singapore: Eastern Universities Press. https://doi.org/10.1093/elt/57.3.269

Hong, W. M. (2008). Lexical Aspect and L1 Influence on the Acquisition of English Verb Tense and Aspect among the Hong Kong Secondary School Learners. (Ph.D. dissertation, Hong Kong Polytechnic University (Hong Kong), Hong Kong. Retrieved April 13, 2018, from Dissertations \& Theses: Full Text database).

Hu, G. (2005). Contextual influences on instructional practices: A Chinese case for an ecological approach to ELT. TESOL Quarterly, 39, 635-660. https://doi.org/10.2307/3588525

Johnson, D. W., \& Johnson, R. T. (2009). An educational psychology success story: Social interdependence theory and cooperative learning. Educational Researcher, 38(5), 365-379. https://doi.org/10.3102/ 0013189X09339057

Kanevsky, L. (2011). Deferential differentiation: What types of differentiation do students want? Gifted Child Quarterly, 55(4), 279-299. https://doi.org/10.1177/0016986211422098

Lantolf, J. P., \& Poehner, M. E. (2010). Dynamic assessment in the classroom: Vygotskian praxis for second language development. Language Teaching Research, 15(1), 11-33. https://doi.org/10.1177/1362168 810383328

Mansoor, S. (2004). The medium of instruction dilemma: Implications for language planning in higher education. In S. Mansoor, S. Meraj, \& A. Tahir (Eds.), Language policy, planning, \& practice: A South Asian perspective. Karachi: Agha Khan University.

McLeod, D. (1992). Research on affect in mathematics education: A reconceptualization. In D. Grows (Ed.), Handbook of research on mathematics teaching and learning (pp. 575-596). New York: McMillan.

Mekhlafi, A. M., \& Nagaratnam, R. P. (2011). Difficulties in teaching and learning grammar in an EFL context. Oman International Journal of Instruction, 4.

Mundy, K. E. (2008). Comparative and International Education: Issues for Teachers. Toronto; New York: Canadian Scholars' Press, Teachers College Press.

Mustafa, Z. (2011). Tyranny of language in education, the problems and its solutions. Karachi: Ushba Publishing International.

Nunan, D. (2003). The impact of English as a global language on educational policies and practices in the Asian Pacific region. TESOL Quarterly, 37, 589-613. https://doi.org/10.2307/3588214

Phan, L. H., Joyce, K., \& Brendan, C. (2013). Nation building, English as an international language, medium of instruction, and language debate: Malaysia and possible ways forward. Journal of International and Comparative Education, 2(2), 58-71. https://doi.org/10.14425/00.50.27

Qayyum, A., \& Atif, K. (2015). Impact of Colonial rule on today's educational system of Pakistan. Journal of Education Research, 2(9), 51-58.

Rahman, T. (1996). Language and politics in Pakistan. Karachi: Oxford University Press.

Rahman, T. (2004). Denizens of alien worlds: A study of education, inequality and polarization in Pakistan. Karachi: Oxford University Press. 
Rassool, N., \& Mansoor, S (2007). Contemporary issues in language, education and development in Pakistan. In N. Rassool (Ed.), Global issues in language, education and development: Perspectives from postcolonial countries (pp. 218-244). Clevedon: Multilingual Matters. https://doi.org/10.21832/9781853599538-010

Reis, S. M., McCoach, D. B., Little, C. A., Muller, L. M., \& Kaniskan, R. B. (2011). The effects of differentiated instruction and enrichment pedagogy on reading achievement in elementary schools. American Educational Research Journal, 48(2), 462-501. https://doi.org/10.3102/0002831210382891

Shamim, F. (2011). English as language for development in Pakistan: Issue, challenges and possible solution. British Council, United Kingdom.

Shammen, N. (2004). Language attitude in multilingual primary school in Fiji. Language, Culture and Curriculum, 17(2), 1-13.

Tong, F., Lara-Alecio, R., Irby, B., Mathes, P., \& Kwok, O. (2008). Accelerating Early Academic Oral English Development in Transitional Bilingual and Structured English Immersion Programs. American Educational Research Journal, 45(4), 1011-1044. https://doi.org/10.3102/0002831208320790

UNESCO. (2000). World Education Forum: Dakar Framework for Action 2000. Paris: UNESCO.

Wiriyachitra, A. (2001). English Language Teaching and Learning in Thailand in this Decade. Thai TESOL, 14.

\section{Copyrights}

Copyright for this article is retained by the author(s), with first publication rights granted to the journal.

This is an open-access article distributed under the terms and conditions of the Creative Commons Attribution license (http://creativecommons.org/licenses/by/4.0/). 